\title{
Research on a control system based on stepping motor for ship's controllable pitch propellers
}

\author{
Czesław Dymarski, Prof. \\ Gdansk University of Technology
}

ABSTRACT

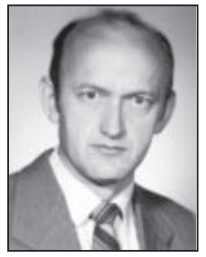

This paper presents description of a laboratory stand for testing servo-mechanisms of ship low-power CP propellers, as well as a remote control system for such propellers, based on electric stepping motor. Also, are presented results of the first series of tests of the control system, carried out on non-loaded CP propeller by applying stepped values of propeller pitch at two values of rotational speed of the stepping motor.

Keywords: ship controllable pitch (CP) propellers, hydraulic drive and control, control systems

\section{INTRODUCTION}

Ship's CP propellers have experienced their dynamic development and their applications on new built ships have systematically increased for a few dozen years. They are the most frequently applied type of propellers on ships required to have high manoeuvrability. The increasing popularity of the CPPs results from many crucial advantages they show. As compared with fixed screw propellers they are characterized by the following favourable features:

a) possible use of full power output in every, even entirely different service conditions;

b) better satisfying different demands expected from towing vessels (e.g. tugs, fish trawlers, minesweepers), namely:

- as large as possible towing power available during towing operations,

- as large as possible speed available in free-floating conditions;

c) possible maintaining the rotational speed of driving engine at changeable ship's speed and in various service conditions, constant, that is very important for ships equipped with shaft generators and pumps;

d) possible fast changing direction of thrust action without necessity of changing direction of propeller's shaft rotation, which is associated with a few additional advantages, namely:

- it makes it possible to apply simpler, less expensive and more reliable non-reversible driving engines;

- it significantly lowers the time necessary for propeller reverse from ,, full ahead" to ,, full astern" as compared with that of reversible driving engine;

- it makes it possible to shorten twice ship stopping distance and time;

- it makes service life-time of engine longer by elimination of significant number of stopping and starting operations during manoeuvres, e.g. in ports; such manoeuvres may be executed at very low ship speed of the order of $0.5 \div 1 \mathrm{~m} / \mathrm{s}$, whereas in the drives with fixed propeller the stable ship speed amounts to $2 \div 3 \mathrm{~m} / \mathrm{s}$ due to engine rotational speed limited from below;

- possible automation and remote control of CPP systems and of the entire propulsion system and in consequence - possible lowering number of crew members (unattended mode of power plant operation), better protection of engine against overloading, improved safety at sea, lower fuel oil consumption.

e) lower torsion stresses in shafting, experienced during changing direction of rotations as compared with those in propulsion systems with fixed propeller.

f) simpler driving system of steam turbine power plant due to lack of astern-drive turbine.

The CPPs show also some disadvantages out of which the following are the most important :

a) greater design complexity and in effect lower reliability of such system,

b) greater investment and operational costs and higher qualifications demanded from operators,

c) greater susceptibility to cavitation at the root of blades (at boss) because of their limited breadth and in consequence greater thickness in this zone.

d) rather lower hydrodynamic efficiency of the CPP by about $3 \%$ as compared with that of fixed propeller, which mainly results from a greater boss diameter, however that does not lead to a lower ship propulsion efficiency in a given service time at variable operational conditions.

Already since the beginning of the 1970s The Faculty of Ocean Engineering and Ship Technology, Gdańsk University of Technology has been engaged with the above described topics, by realizing important $\mathrm{R} \& \mathrm{D}$ investigations at first for the Mechanical Works Zamech, Elblag, and next also for Polish Navy and private owners of fishing vessels. In 1991 at the Faculty a CP propeller was manufacture and a laboratory stand for its testing was built. The propeller, though of a low power, was fitted with a hydraulic pitch control servomechanism. In it a slide 
timing gear of negative-lap, located in stationary system, was used. Stability and accuracy of operation of the servomechanism was the subject of the research carried out in a broad range of external load simulations, results of which was published in $[1,2]$. And, the servomechanism was equipped only with a local system of propeller pitch setting.

The gained experience was used for the designing, manufacturing and testing of two CP propellers intended for small fishing vessels. In Fig. 1 is shown the photograph of one of the propellers during the tests at the Faculty's laboratory. Principle of operation, load calculations and results of the

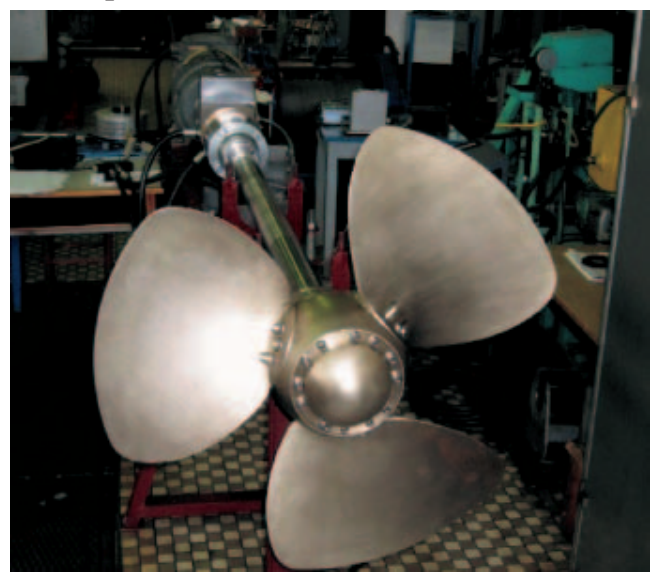

Fig. 1. Low-power CP propeller placed at the Faculty's laboratory test stand laboratory and service tests of the servomechanism applied to the propeller were presented in $[3 \div 7]$. In the servomechanism a slide positive-lap timing gear different from that used for the laboratory test stand, was applied, that required to elaborate an appropriate remote control system activated from the ship's bridge.

\section{DESCRIPTION OF THE LABORATORY TEST STAND}

The existing CP propeller and laboratory test stand was supplemented with the remote control system in order to satisfy current needs. Taking into account present demand for the CPPs in Poland, mainly from the side of small-ship owners, one decided to choose a relatively simple and cheap system of the kind, fitted with an electric stepping motor. The design of such system was presented in detail in [8].

Realization of the above mentioned research task required to do many preparatory operations on the existing laboratory test stand. For the reason that the CPP's servomechanism in question is intended for its using not only in research and education but also for installing onboard small fishing boats mainly, it was decided to fit it with the remote control system capable of making it possible to automate the whole propulsion system easily. Schematic diagram of the servomechanism together with hydraulic and measuring systems is presented in Fig. 2. Two-lever pitch setting unit with possibility of switching the

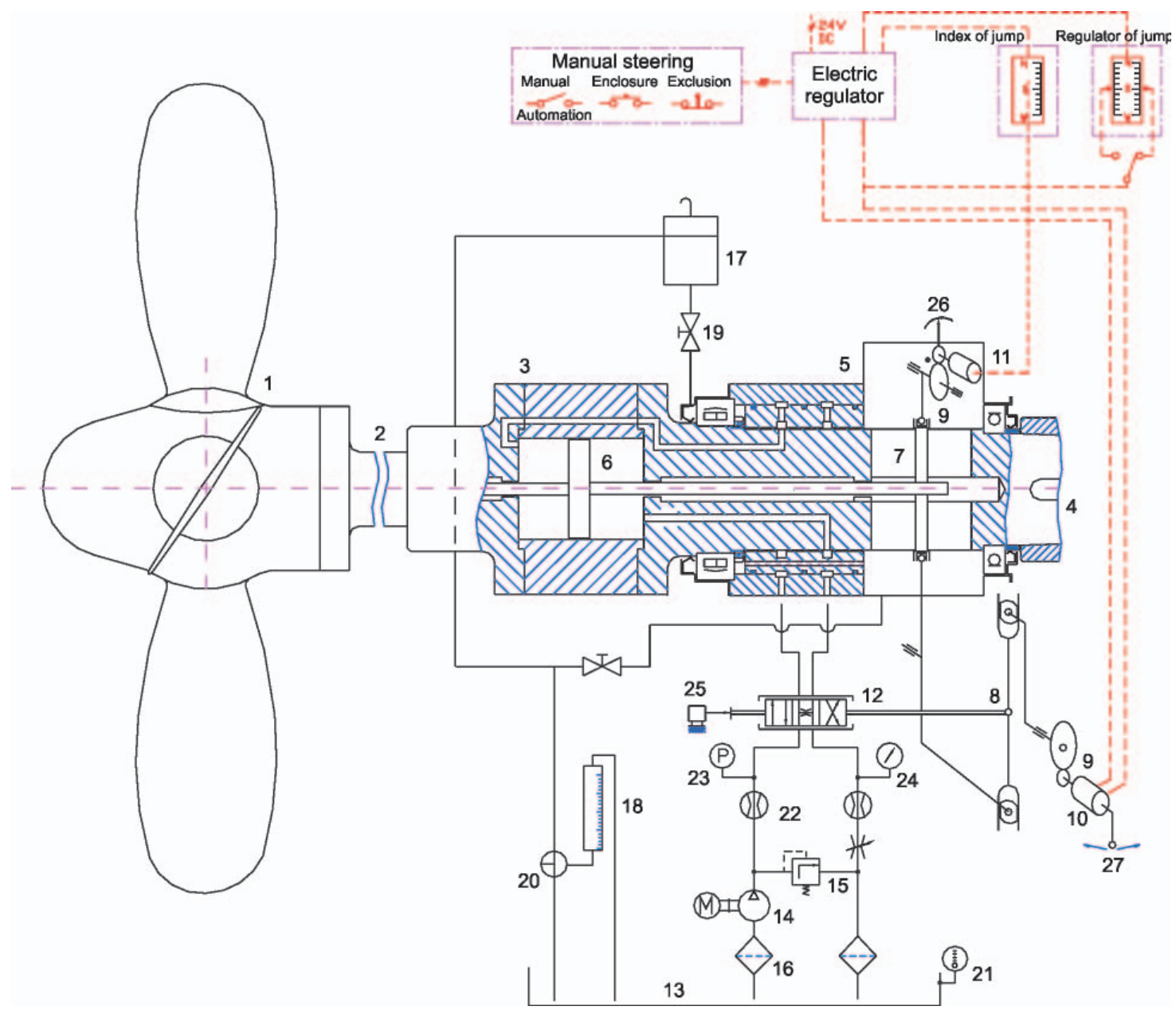

Fig. 2. Schematic diagram of the laboratory test stand for controllable pitch propellers.

Notation: 1 - CPP; 2 - propeller shaft; 3 -flange coupling; 4 - intermediate shaft; 5 -oil timing box; 6 - hydraulic cylinder of propeller pitch control mechanism; 7 - real pitch signal input system; $\boldsymbol{8}$ - feedback lever system; $\mathbf{9}$-toothed transmission gear; 10 - stepping motor; 11 - rotation angle indicator, 12 - three-position four-way distributor of negative laps; 13 -oil tank; 14 constant capacity oil pump; 15 - overflow valve; 16 - oil filter; 17 - gravitational oil tank; 18 - measuring tank; 19 -cut-off valve; 20 -three-way valve; $\mathbf{2 1}$ - temperature gauge; 22 -flow-meter; 23 - pressure gauge; 24 -manometer; 25 -linear displacement gauge; 26 -real pitch indicator; 27 - propeller pitch local setting lever 
set values, is applied to it, that makes it possible to examine the system's response to stepped changes of the input values.

Two photographs of the tested servomechanism together with the control desk and measurement recording equipment are shown in Fig. 3, and the photograph of the remote control desk - in Fig. 4.
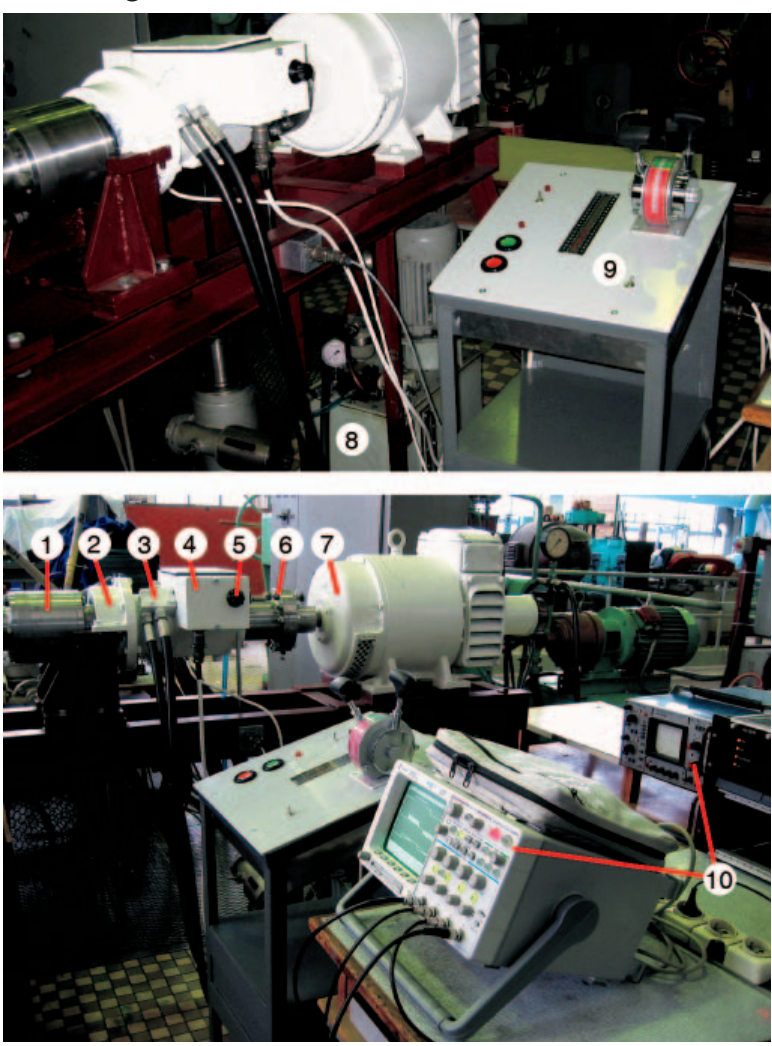

Fig. 3. The laboratory stand for testing the CP propeller servomechanism. Notation: 1 - hydraulic pitch control cylinder placed between flanges of propeller shaft and intermediate shaft; 2 - angular bearing; 3 - hydraulic distributor; 4 -oil timing box with internal control unit; 5 -hand wheel for propeller pitch local setting; 6 -clutch; 7 -shaft driving DC motor; $\boldsymbol{8}$-hydraulic supply unit; $\mathbf{9}$-remote control desk; 10 -measurement recording equipment

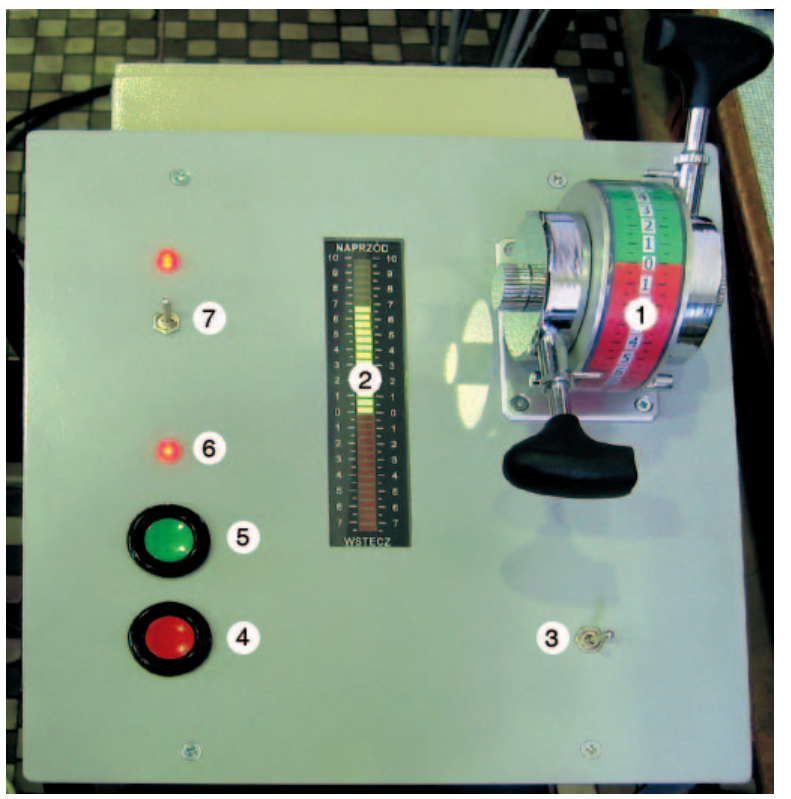

Fig. 4. The control desk of the tested CP propeller.

Notation: 1 -two-lever handle for propeller pitch setting; 2 -electronic indicator of real propeller pitch; 3 - change-over switch of setting handle; 4 - cut-out; 5 - switch-in; 6 - control lamp; 7 - change-over switch for remote or local control

\section{LABORATORY TESTS}

The performed tests were aimed at the checking of correctness of operation of the built remote control system in cooperation with the existing servomechanism, as well as of stability and accuracy of the whole propeller pitch control system without any external load. The only acting load was that due to friction forces and very small inertia forces of moving elements of the servomechanism. The greatest share in the load was associated with friction forces of the piston sealing rings and - to a little smaller extent - the piston rods of the hydraulic cylinder.

Influence was also checked of one of the adjustable quantities, namely rotational speed of stepping motor, on dynamics of motion of the system's elements and pitch setting accuracy.

\section{Step change of the propeller blade-angle setting from $\alpha=0$ to $\alpha=9^{\circ}$, and next back to $\alpha=0^{\circ}$}

The recorded runs of:

$\Rightarrow$ the electronic control operation state $u_{z}$

$\Rightarrow$ the axial displacements of the hydraulic distributor slide, $\mathrm{x}$,

$\Rightarrow$ values of the blade-angle setting $\alpha_{\mathrm{z}}$ and

$\Rightarrow$ real values of the angle $\alpha$

are presented in Fig. 5. The measurements were performed at the pulse generator frequency $v=7.5[\mathrm{~Hz}]$ which - for the stepping motor executing 200 steps per revolution - ensures its shaft's rotational speed $\mathrm{n}=2.25[\mathrm{rpm}]$. Hence the duration time of one working cycle of the system, $t$, was equal to 133.3 [ms] (milliseconds).

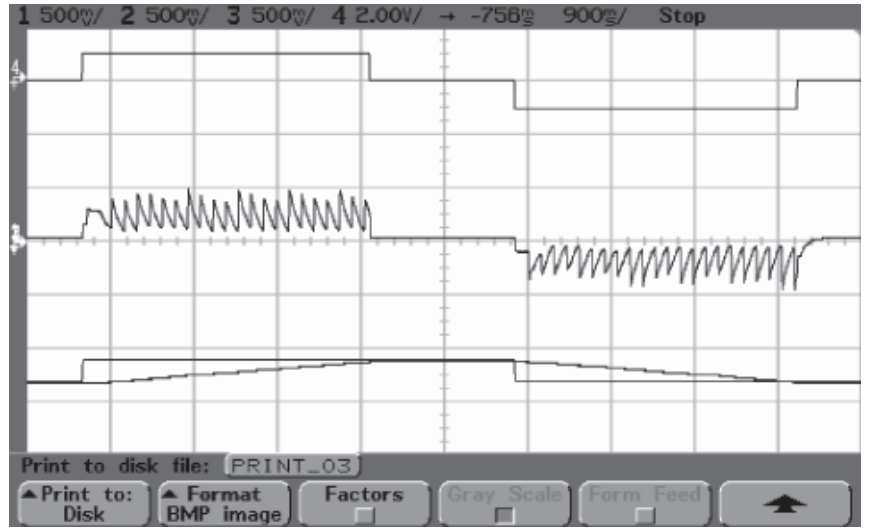

Fig. 5. The oscilloscope screen's photograph which shows the recorded runs of: the control signal $u$ displacements of hydraulic distributor slide, $x$, values of the set propeller blade angle $\alpha_{z}$, and the real one $\alpha$

When only the propeller pitch setting handle is inclined (at the test stand the step action switch is activated) a constant voltage signal is generated which triggers the stepping motor working and maintains constant until the value of the real blade angle $\alpha$ is equal (within the set accuracy limits) to that of the set angle $\alpha_{\mathrm{z}}$ Then the feed-back system switches off the control signal. The inclination of the propeller pitch setting handle in the opposite direction to its initial position will trigger again analogous process of propeller pitch changing until its new set value it attained, then the entire process is stopped.

The run of the hydraulic distributor slide displacements is worth attention. Every "step" rotation angle of the stepping motor shaft makes initially the distributor slide displacements violent and in effect starts delivery of oil under compression to one of the cylinder chambers, piston motion and propeller pitch 
change. With a view of the very small value of the set „step" equal to $1.8^{\circ}$, realization of such real pitch change makes the deviation relatively fast decreasing and, due to operation of the feed-back system, the slide gradual coming-back towards its initial position. In the meantime the successive „step” of motor shaft rotation, successive stepwise slide displacement as well as propeller pitch change occur, and the above described cycle of operations is repeated until a set pitch change value executed this way is finally attained.

It is worth noting a little smaller displacement of the slide during the first step just after starting the pitch changing process both forward and aft. In the opinion of this author it is caused by a relatively greater drag of the slide due to a somewhat thicker and colder oil layer adhering to surfaces of small pistons and cylinder before starting than that observed during fast cyclic displacements.

Values of the slide displacements $\mathrm{x}$ and frequency of their occurrence depend on the stepping motor rotational speed and flow rate of oil delivered to the distributor.

\section{Step change of the propeller blade-angle setting from $\alpha=0$ to $\alpha_{\max }=34^{o}$, and next back to $\alpha=0^{\circ}$}

The runs of $u_{z}, x, \alpha_{z}$ and $\alpha$ recorded during this test are presented in Fig. 6 . The recording of the measurements was computer-aided. Number of the measurements is marked on the horizontal axis of the diagram.

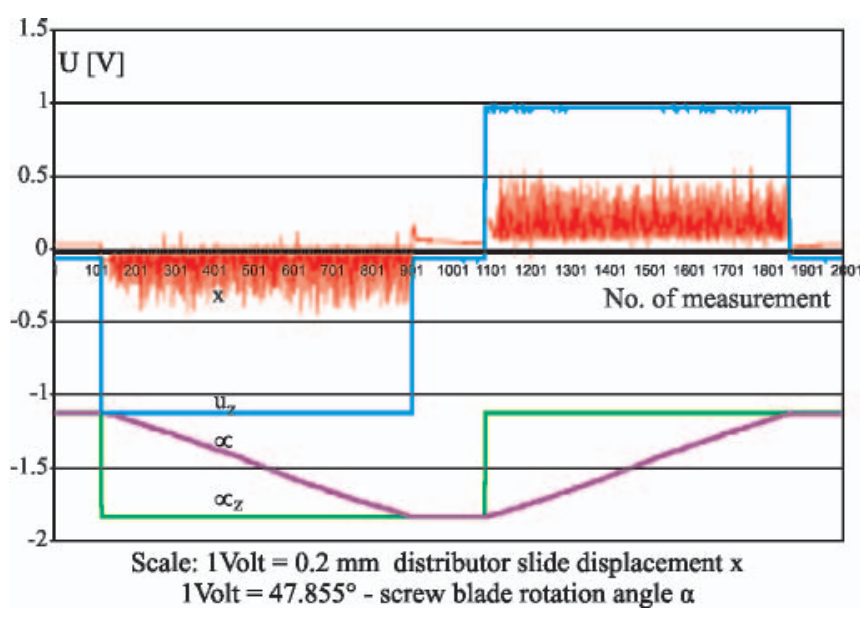

Fig. 6. Measured runs of: $\boldsymbol{u}_{z}$ - control signal, $\boldsymbol{x}$-hydraulic distributor slide displacement, $\boldsymbol{\alpha}_{z}$ and $\boldsymbol{\alpha}$ - set and real values of propeller pitch during its step setting change from $\alpha=0$ to $\alpha_{\max }=34^{\circ}$, a then back to $\alpha=0^{\circ}$

On the vertical axis are given values of voltage signals of particular measured quantities, and their scale - below the diagram. The zero-point of the axis does not correspond with zero value of measured quantity.

The character of the recorded runs is similar to those discussed in the preceding chapter with one exception, namely: the slide's movement in the instant of termination of the returning control process. In this case fast return of the slide from a working position causes its instantaneous displacement behind the middle one. This can be supposed to be caused first of all due inertia forces of the fast moving slide, as well as a greater accuracy of the computer-aided measurements.

Analyzing the run of propeller blade-angle setting changes one should state that it is stable despite the non-uniform velocity of motion and that the achieved setting accuracy is sufficiently correct. The diagrams of the measured values of $\alpha$ and $\alpha_{z}$, after realization of the task, practically coincide.

\section{The test of influence of change of stepping motor speed on operation of the system}

The test was performed in such a way that the step change of propeller pitch from „full astern" to „full ahead" was set from $\alpha_{\text {min }}=-24^{\circ}$ to $\alpha_{\max }=34^{\circ}$, and during realization of the process at the same velocity as in the first described test the stepping motor rotational speed was temporarily increased more than twofold (the pulse generator frequency $v=15.6[\mathrm{~Hz}]$, the motor rotational speed $\mathrm{n}=4.68[\mathrm{rpm}]$ and cycle period $\left.\mathrm{t}_{\mathrm{c}}=64.1[\mathrm{~ms}]\right)$. The computer-recorded results made it possible to elaborate the runs of the measured quantities $\mathrm{u}_{\mathrm{z}}, \mathrm{x}, \alpha_{\mathrm{z}}$ and $\alpha$, shown in Fig. 7.

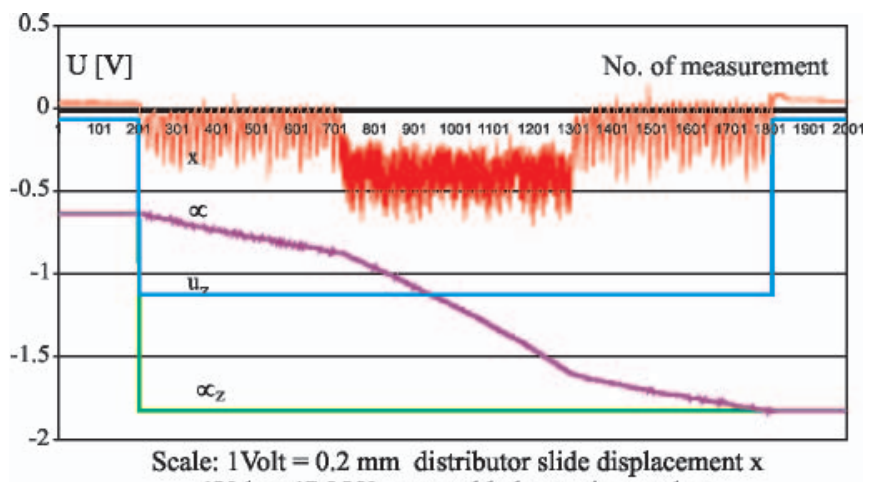

1 Volt $=47.855^{\circ}$ - screw blade rotation angle $\alpha$

Fig. 7. Measured runs of : $\boldsymbol{u}_{-}$- control signal, $\boldsymbol{x}$-hydraulic distributor slide displacement, $\boldsymbol{\alpha}_{z}$ and $\boldsymbol{\alpha}$ - set and real values of propeller pitch during its step setting change from $\alpha_{\text {min }}=-24^{\circ}$ to $\alpha_{\text {mo }}=34^{\circ}$ together with changing the rotational speed of stepping motor from $n_{1}=2.25[\mathrm{rpm}]$ (Generator frequency $v=7.5[\mathrm{~Hz}]$; cycle period $\left.t_{c}=133.3[\mathrm{~ms}]\right)$ to $n_{2}=4.68[\mathrm{rpm}]$ $(v=15.6[\mathrm{~Hz}] ; t=64.1[\mathrm{~ms}])$

The run of the distributor slide motion should be discussed here. When only the rotational speed of the stepping motor increased and the single cycle period decreased twofold, the average value of the displacements $\mathrm{x}$ increased almost twofold too. It can be explained is such a way that after the motor speed increasing and the working cycle period shortening the closing slide had been earlier displaced further than at the lower speed and in effect its successive displacement had been commenced in the instant when it had been much more distant from the middle position than in the preceding step. Consequently, successive displacements of the slide occurred at a more and more greater value of the average displacement. This way the oil flow rate and cylinder piston speed were increasing. After several cycles, value of the average displacements of the slide became fixed on a new, higher level. When only the motor rotational speed decreased the slide displacement cycles went consequently on a lower level.

\section{CONCLUSIONS}

The presented tests of the CP propeller servomechanism together with the remote control system are only the first, but very important phase of the necessary research on devices of the kind. They were aimed at the checking of quality and accuracy of realization of the system's main tasks during its operation without any load. The achieved results which showed the correct and sufficiently accurate operation of the servomechanism justify purposefulness of continuation of such research.

The research should be carried out in the conditions which simulate possibly exactly real service conditions especial- 
ly in the range of values and character of external loads applied to the servomechanism. However to this end it is necessary to design and manufacture a special device for setting a given value and direction of the loading exerted to the pitch control mechanism. It is assumed to locate the device in a rotating system, in the rear part of propeller boss, instead of the propeller cap. The similar device was already used in testing the CP propeller for KR10 fishing cutter [3].

Moreover it is planned to investigate the influence of increasing the gear ratio of the toothed transmission gear (9) placed between the stepping motor (10) and the lever (8), (see Fig. 2), on dynamic behaviour of the system under operation.

To sum up, positive results of the planned research would make it possible to offer the relatively simple and inexpensive solution mainly for application to small modern floating units, especially fishing ones.

\section{BIBLIOGRAPHY}

1. Dymarski C.: Laboratory tests of a hydraulic servomechanism of low-power controllable pitch propeller (in Polish). Marine Technology Transaction, Polish Academy of Sciences - Branch in Gdańsk, Marine Technology Committee. Vol. 8. 1997.

2. Dymarski C.: Laboratory investigations of the stern tube bearings and pitch control mechanism of the low-power $C P$ propeller with screw-toothed gear. Polish Maritime Research No 3 September 1998, Vol. 5.

3. Dymarski Cz.: Pitch Control Servomechanism for a Low Power Rate CP Propeller. Marine Technology Transaction, Polish Academy of Sciences-Branch in Gdańsk, Marine Technology Committee. Vol. 12, 2001.
4. Dymarski P., Dymarski Cz.: Curvilinear Panels and Higher Order Dipole Distribution Method for Ducted Propeller Flow Calculations. Marine Technology Transaction, Polish Academy of Sciences-Branch in Gdańsk, Marine Technology Committee. Vol. 12, 2001.

5. Dymarski Cz.: The hydraulic drive and control of the equipment of the small fishing cutter. Marine Technology Transaction, Polish Academy of Sciences - Branch in Gdańsk, Marine Technology Committee. Vol. 13, 2002.

6. Dymarski Cz.: A ship CP propeller servomechanism (in Polish). Proceedings of 4th Conference ,Shipbuilding and Ocean Engineering": Reliability and Safety of Transport Systems. Międzyzdroje, June 2002. Publishing House of Szczecin University of Technology.

7. Dymarski Cz.: A propulsion system for small fishing vessel (in Polish). Proceedings of $3^{\text {rd }}$ International Scientific - Technical Conference EXPLO - DIESEL \& GAS TURBINE'03. Gdańsk - Miedzyzdroje - Lund (Sweden), May 5 - 9, 2003.

8. Dymarski Cz., Blekiewicz T.: Elaboration of a remote control system based on stepping motor, intended for CP propeller, and a mechanical transmission gear of negative feedback ensuring stability of a set position (in Polish). Research reports, Faculty of Ocean Engineering and Ship Technology, Gdańsk University of Technology, Gdańsk 2005.

\section{CONTACT WITH THE AUTHOR}

Assoc. Prof. Czesław Dymarski Faculty of Ocean Engineering and Ship Technology,

Gdańsk University of Technology Narutowicza 11/12 80-952 Gdańsk, POLAND e-mail : cpdymars@pg.gda.pl

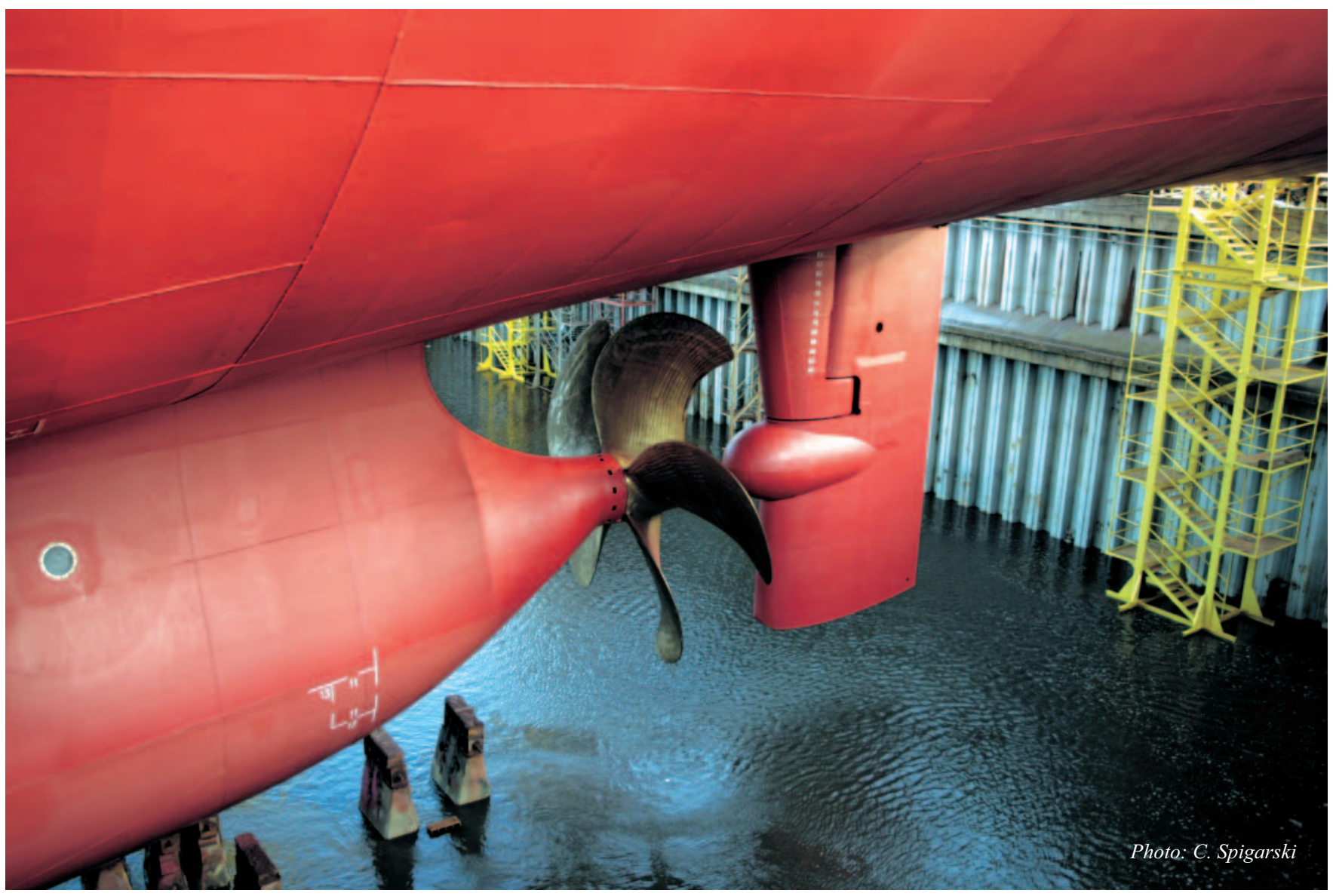

